\title{
Behavioral Intention \\ Of Young Consumers \\ Towards The Acceptance \\ Of Social Media \\ Marketing in Emerging \\ Markets
}

Nguyen Thi Phuong Thao, Ph.D.,

Dalat University,

The Faculty of Economics \& Business

Administration,

Lamdong, Vietnam,

ORCID: 0000-0002-3727-2582.

Nguyen Van Anh, Ph.D.,

Dalat University,

The Faculty of Economics \& Business

Administration,

Lamdong, Vietnam,

ORCID: 0000-0003-3640-1482.

\section{Introduction}

In recent years, we have witnessed the explosion of social media tools (Facebook, Twitter, LinkedIn, Youtube, Pinterest, Instagram, etc.) and almost any of us are involved into these online communities. The explosion of social media tools has provided millions, even billions of people with the opportunity to build and share content on a huge scale, which was almost impossible before (Romero et al., 2011). Today, Internet users are accustomed to communicating, connecting with friends as well as sharing data, information, images or videos through social media tools. These tools allow users to search, organize, share, annotate and contribute content in a constructive manner (Parra-López et al., 2011). Research by Luo, Zhang, \& Duan (2013) considers social media to be an important indicator that determines the equity value of businesses and has a more accurate predictive value than behavioral statistics Regular online consumption (Luo et al., 2013). At the present time, the Internet has received a great deal of attention, and has 
attracted the attention of the media, the public and marketing researchers more than any other technology (O'Cass, Fenech, 2003).

Therefore, social media tools are an important marketing channel for businesses and marketers to reach a large number of current and potential customers. Marketing units are using this channel to advertise products, attract attention and connect with customers. The explosion of the Internet, coupled with the rapid increase in the number of users, provides an opportunity for companies to easily target their target customer base and introduce their products through media websites. society. Companies are now making great efforts to optimize the use of social media to market their products to the public. More and more companies are investing in customer-driven technology online to gain more market share from the online market (Al Qeisi, Al-Abdallah, 2014). Marketing through social media enables businesses to gather quick feedback from their customers and find market trends. Organizations and businesses are gradually shaping and maximizing the power of social media on the Web 2.0 platform (Thackeray et al., 2008). In the current Internet era, organizations strive to achieve success thanks to their presence on the Internet and contribute to improving brand awareness in the market (Bansal, 2015).

Marketing through social media has become an important channel to listen and research on customer behavior, identify the market and open up new opportunities (Agrawal, Kaur, 2015). Marketers need to recognize the influence of social media on their buying behavior and whether customers are willing to receive marketing through social media. Therefore, it is essential to research marketing intent through social media, to help manufacturers and retailers better understand the nature of consumer behavior and help identify weaknesses in their promotional activities through social media. By understanding the nature of consumer behavior, marketers and sellers can predict customers' buying behavior. This research can also be applied to establishing regulations and creating marketing strategies as well as formulating plans based on research findings.

The object of this study is to identify the factors influencing to marketing through social media of young users in the developing market. We create a model framework for adoption of social media marketing which is based on UTAUT by discovering key additional constructs to be included into TAM and personal constructs. This study will be a significant attempt by providing factors that mostly affect the consumers' Preference/behavior towards Social Media Marketing. This study can help the manufacturers and retailers to understand the nature of consumers' acceptance behavior and to discover the weaknesses 
of their promotional activities through social media. By understanding the nature of consumers' acceptance behavior, marketers and sellers can predict the consumers' purchase behavior. This study will be helpful for policy making and establishing marketing strategies and formulating plans on the basis of the findings of this study.

\section{Theoretical background and research model}

\subsection{Important concept}

\subsubsection{Social media}

Researchers and media experts have come up with different concepts about social media. According to techtarget.com, social media is a collection of online communication channels to interact, share content, and collaborate (Rouse, 2018). Social media includes a wide range of online media forums such as blogs, discussion boards of companies or chat rooms, service evaluation pages, online discussion pages and websites. society (Mangold, Faulds, 2009).

Social media sites rely heavily on users to create and contribute content; divide different content based on tags, reviews, comments; build online relationship; and join online communities (Guy et al., 2010). Vinerean et al. (2013) also confirmed that the meaning of social media can be derived from the two words that make up it, including: Communication is the advertising and communication of ideas or information. through publication. Society implies interaction between individuals within a group or community. Together, social media is meant to be a communication platform created and maintained by interpersonal interactions through a certain tool or intermediary (Vinerean et al., 2013).

\subsubsection{Social media marketing}

Social media platforms have become a fertile ground for marketing. They act as an effective channel to advertise products and promote brands. According to techtarget.com, social media marketing is taking advantage of social media to help companies spread the brand and expand the reach of customers with the purpose of creating content that is interesting enough. for users to share them with other relationships in their social networks. Marketing through social media has great advantages such as low cost, information is shared in many

71

NGUYENTHI PHUONG THAO

NGUYENVAN ANH 
different formats at a fast pace to a large community and especially interaction with people. use (Rouse, 2018).

Social media marketing is an attempt to use social media to convince consumers that their company, product or service is worthwhile. Marketing through social media through major channels like online communities, social networks, marketing blogs and more. Social media marketing is primarily based on the Internet but it has something in common with non-Internet activities or marketing methods such as word of mouth (Neti, 2011).

The two basic elements of social media marketing are EWOM and advertising through social media. Marketing through social media is gradually shifting the attention of marketers from word of mouth (WOM) to electronic word of mouth (EWOM). Social media marketing can benefit some organizations in at least two aspects: economically and effectively communicating with customers; and taking advantage of word of mouth communication among customers (Pan et al., 2014).

\subsubsection{Electronic word of mouth (EWOM)}

Electronic word of mouth (EWOM) is also known as viral marketing. Thirtyfour percent $(34 \%)$ of bloggers post their opinions on products and brands while twenty-five percent (25\%) of the search results for the world's 20 largest brands link to internal. content created by users. According to Montgomery (2001), EWOM is a form of marketing that impacts customers with advertising messages and spread from person to person as a flu virus. People often communicate through word of mouth and social media when they are approaching a new product, service or idea (Mangold, Faulds, 2009).

In fact, EWOM can have positive or negative meanings for a company. When the positive message spreads quickly, it can effectively bring free advertising to the company, build brand awareness as well as increase sales (Longart, 2010). Marketers today need to focus on creating content that can be easily shared between platforms, otherwise they will restrict the word of mouth about their brand but also need censorship and failure. take care to avoid giving results that go against expectations.

\subsubsection{Social media advertisement}

Social media advertisement is part of social media marketing by optimizing the use of the Internet's social media platform to deliver messages to potential 
customers. Online advertising is part of a website, designed to provide marketing messages to attract customers who choose to buy products or services (Mohammed \& Alkubise, 2012).

For companies wishing to promote their products or services, online advertising can reach more people, be more targeted and more cost-effective than advertising through newspapers. magazines, traditional magazines or TV (Manolescu \& Laghaeian, 2008). The rate and effectiveness of ads spreading on Facebook depends on the usage and engagement of consumers in the application groups on the website, so understanding their psychological personality is very useful. in establishing an optimal operating mechanism to spread advertising (Chu, 2011).

\subsubsection{Theoretical background}

Technology Acceptance Model (TAM) has been interested by many researchers in recent decades. The TAM extends from Theory of Reasoned Action (TRA) of Ajzen and Fishbein (1975), showing that social behaviors are driven by individual attitudes and designed to predict the system information. The model of technology adoption is one of the widely accepted and widely used theories explaining the integration of technology (Gardner, Amoroso, 2004).

Davis (1989) suggested that the TAM model helps to analyze from the perspective of consumers when adopting new technologies. TAM states that when users are introduced to new technologies, there are many factors that influence their decisions (Davis, 1989). TAM is an improvement from models from Theory of Reasoned Action (TRA) and Theory of Planned Behavior (TPB) in predicting people's behavioral intentions. buy (Gentry, Calantone 2002). TAM has become so popular that it is used in most studies of user adoption technology (Lee et al., 2003).

Unified theory of acceptance and use of technology (UTAUT) is a theory that has been recently developed for research to understand more about user adaptations to technologies. UTAUT is a key theory in behavioral research. It reflects the most complete knowledge of years of research on the reception and use of new technologies (Venkatesh et al., 2011). The theory proposes four factors that influence the intent of behavior when using a technology that is performance expectation, effort expectation, social influence and physical condition. Venkatesh et al (2003) also gave definitions for four elements; Performance expectation is the level of usefulness that this new technology will help users achieve by increasing the performance of certain jobs; Expect effort is the level of ease of 
use when users come in contact with this new technology; Social influence is the extent to which users are aware that people around them (family, friends) encourage them to use a new technology; and Material conditions related to users' awareness of available resources and support so that they can perform a certain act (Venkatesh et al., 2003). Sundaravej (2010) studied the reception of educational technologies by users using UTAUT. These findings have shown the credibility and validity of the elements from the model (Sundaravej, 2010). According to Balaid, Yaslam Almatari and Iahad (2013), both TAM and UTAUT models can be applied to intentional studies by using quantitative variables (Balaid et al., 2013).

\subsection{Research model and Hypotheses}

The research model is based on the Technology Acceptance Theory (TAM) and adds elements from the Unified Theory of Technology adoption and use (UTAUT). This integration model includes elements deemed to be best suited to the social media marketing landscape. This model was launched from TAM and added some more elements compared to UTAUT. This model investigates the relationship between attitudes to technology and six independent factors. Three of them come from UTAUT, which are expectations of effort, social influence and physical conditions. The performance expectation factor was not chosen because it is similar to the useful perception in the TAM model. From TAM, pick out useful insights and attitudes toward technology (attitudes towards social media advertising and attitudes to word-of-mouth).

Similarly, an easy-to-use awareness element was not selected because it was similar to the expected effort in UTAUT. It should be noted that some personal characteristics included in UTAUT and TAM may affect user attitudes. In this study, there are two factors that bring individual characteristics of users to better understand their attitudes: the level of user participation in social media and the perceived risks associated with buying pine products through social media platforms. Martins et al (2014) have concluded that with regulatory effects from models with additional risk perception factors than UTAUT models may be better than other models in explaining intentions. of consumers (Martins et al., 2014). And the integrated model was formed from taking into consideration the above factors. In this model there are six factors, and they all have a direct impact on user behavior. Attitude will also be a direct determinant of user intent. In the TRA and TPB, it is stated that attitude is a prerequisite for giving intention and intention for behavior always precedes actual behavior (Knutsen, 2005). 


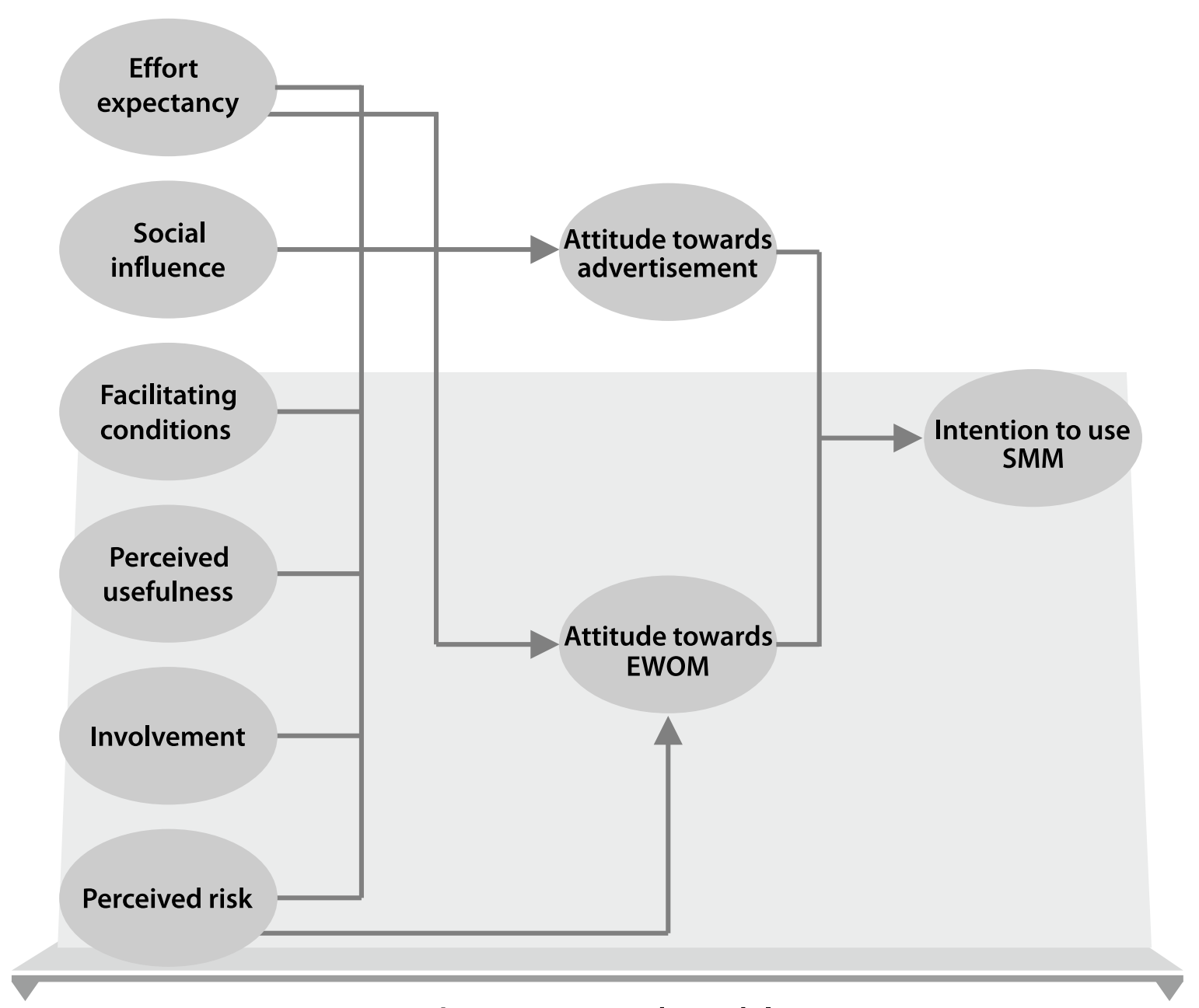

Figure 1. Research model

Source: own study

Hypotheses:

Expectation of the effort is determined by the level of familiarity and use of the system, here is advertising on social media and word of mouth. If the exposure to these technologies is not much difficult, users will have more confidence and first impression on them. Therefore, the author makes the following hypotheses:

Hypothesis H1-1: Effort expectancy has a positive effect on the attitude toward advertisement on social media.

Hypothesis H1-2: Effort expectancy has a positive effect on the attitude toward EWOM on social media. 
According to Venkatesh et al., (2011) social influence is defined as the degree to which an individual perceives that important others believe he or she should use the new system. It was found that the effect of social influence on behavioral intention was found to be contingent on gender, age, experience, and voluntariness, such that it is the strongest for older women in early stages of experience in mandatory contexts.

Hypothesis H2-1: Social influence has a positive effect on the attitude toward advertisement on social media.

Hypothesis H2-2: Social influence has a positive effect on the attitude toward EWOM on social media.

According to (Venkatesh et al., 2003) "facilitating condition is the degree to which an individual believes that an organizational and technical infrastructure exist to support the use of a system". Facilitating conditions is defined as the degree to which an individual believes that an organizational and technical infrastructure exists to support use of the system and it was found that the effect of facilitating conditions on technology use was moderated by age and experience (Venkatesh et al., 2011).For this study we made a change to modify UTAUT by considering indirect relationship between facilitating condition to behavioral intention instead of existing relationship between facilitating condition and use of technology. The reason for this change is that if a consumer who has access to favorable set of facilitating conditions for using social media platforms is more likely to have a higher intention to accept marketing on social media platforms. In general, a consumer with low level of facilitating conditions will have lower intention to use social media marketing. Although UTAUT does not included the effect of facilitating conditions on behavioral intention but some researchers have used this relationship. (Jairak, Praneetpolgrang, \& Mekhabunchakij, 2009) report a positive effect of facilitating conditions on behavioral intention. (Troy et al, 2013) believed that whenever there are constraints on resources, facilitating conditions will become an important predictor of behavioral intention.

Hypothesis H3-1: Facilitating conditions has a positive effect on the attitude toward advertisement on social media.

Hypothesis H3-2: Facilitating conditions has a positive effect on the attitude toward EWOM on social media.

Davis (1989) defines that perceived usefulness is the extent to which a person believes that using a particular system would enhance his job performance. 
Perceived usefulness is defined as the extent to which individuals believe that using the new technology will enhance their task performance. The usefulness construct has been used extensively in information systems and technology research, and has strong empirical support as an important predictor of technology adoption (Mathieson, 1991). Other studies providing evidence of the significant effect of perceived usefulness on intention are from Davis et al., (1989); Venkatesh and Morris (2000). The ultimate reason for people to utilize M-Commerce is that they find it useful to their tasks, transactions or everyday living. An individual evaluates the consequences of their behavior in terms of perceived usefulness and base their choice of behavior on the desirability of the perceived usefulness. Hence, we posit that:

Hypothesis H4-1: Perceived usefulness has a positive effect on the attitude toward advertisement on social media.

Hypothesis H4-2: Perceived usefulness has a positive effect on the attitude toward EWOM on social media.

The purpose of including involvement in the research model is to discuss the relationship between user involvement in social media and consumer attitude and intention to accept social media marketing. According to free dictionary "involvement is the act of participation in some activities". (Petty, Cacioppo, \& Goldman, 1981) stated that high involvement cause person to achieve motivation for information processing and comparing different items. By including involvement it is to be considered that the consumer who is actively involved in social media activities is more likely to have a higher intention to accept social media marketing.

Involvement is a motivational state induced by an association between an activated attitude and the self-concept (Johnson \& Eagly, 1989). (Vermeir \& Verbeke, 2006) states that consumers with high involvement have more positive attitudes and are more willing to purchase sustainable products.

In addition, the manipulation of involvement contributed to increased involvement levels of consumers. In the high involvement conditions, the subjects would be affected personally by the advocated change, whereas in the low involvement conditions they would not (Petty et al., 1981). (Ahmad, Kyratsis, \& Holmes, 2012) mention that appropriate involvement can lead to innovation adoption decisions compatible with structural and cultural contexts. Hence, we posit that: 
Hypothesis H5-1: Involvement has a positive effect on the attitude toward advertisement on social media.

Hypothesis H5-2: Involvement has a positive effect on the attitude toward EWOM on social media.

M.-C. Lee (2009) define perceived risk as the subjectively determined expectation of loss by user in contemplating a particular online transaction. According to (Havlena \& DeSarbo, 1991) risk perception is related to the fact that consumers are often uncertain about the outcome of a choice between brands in a particular product class and can become quite concerned about the consequences of a poor or wrong decision. However, consumer's involvement with the purchase decision influences the person's perception of risk (Dowling \& Staelin, 1994).

According to (Lim, 2003) perceived risk is the degree to which individuals believe that if they purchase products or services through the Internet, they will suffer losses. Perceived financial risk, perceived psychological risk, and perceived time loss risk have three sources. Hackers can cause financial losses to consumers by stealing their credit card details. Similarly, consumers may perceive financial losses because of poor product quality, a fear that deceitful vendors disappear overnight and do not deliver(Lim, 2003). Consumers may worry about the performance of the product they are trying to purchase, the possible loss of their time or money, or even other people's judgments about their purchase, until they finally confirm the quality of the product (Ko, Jung, Kim, \& Shim, 2004). In contrast to the expectation about negative influence (Wu \& Wang, 2005) found positive influence of perceived risk on behavioral intention to use.

Indeed, risk perception is one of the main barriers to m-banking adoption in Brazil (Cruz et al., 2010), the most important in China (Laforet \& Li, 2005; Faqih \& Jaradat, 2015) and has a significant relationship with users' attitudes and intention to use m-banking in Iran (Mohammadi, 2015). This construct also has significant relationship with internet banking adoption (Yiu et al., 2007) and with customer's lack of interest in online commercial transactions (Liao et al., 2011). The perception of risk is a significant factor affecting trust (Al-Gahtani, 2011) and affecting mobile banking adoption (Al-Jabri \& Sohail, 2012 and Ha, et al., 2012). As risk perception can generate a negative effect on trust, the researcher included this variable in the model.

A closer look at the relevant studies leads the author to observe that perceived risk is one of the most important obstacles hindering the customers' willingness 
to adopt m-banking (Akturan \& Tezcan, 2012; Hanafizadeh et al., 2014). Accordingly, this study assumes the following hypothesis:

Hypothesis H6-1: Perceived risk has a negative effect on the attitude toward advertisement on social media.

Hypothesis H6-2: Perceived risk has a negative effect on the attitude toward EWOM on social media.

In this study we have included attitude in the research model for finding the relationship between consumer attitude and behavioral intention. According to (Theotokis, Vlachos, \& Pramatari, 2008) recent studies recognize that users have different attitude towards different technologies even if these technologies used to support the same service. According to Venkatesh attitude is Individual's positive and negative feeling about performing the target behavior like using a system. An individual's attitude toward an object is a function of (a) beliefs about the object (Fishbein, 1963). (Jairak et al., 2009) indicate that attitude have positive effect on behavioral intention.

In order to measure attitude towards social media marketing the word technology had been replaced by SMM. For obtaining more accuracy in the research model dealing with attitude towards social media marketing, it will be helpful to partition the attitude into two different constructs. Among these two constructs first will be attitude towards advertisement on social media, and second will be attitude towards electronic word of mouth. For both constructs different items had been included in survey. (MacKenzie \& Lutz, 1989) stated that recent research has identified attitude toward the ad (AAd) as an important construct mediating the effects of advertising on brand attitude and purchase intention. According to (Ling, Piew, \& Chai, 2010) Consumers' attitude towards advertising is a form of psychological judgment, in which this judgment will change over time. Negative attitudes are caused by a variety of factors: popular perception of age and technology, lack of awareness of technology, the feeling that technology is not useful and the feeling that it is too difficult to use (Eisma et al., 2004).

In TAM behavioral intention to use leads to actual usage of IT. Behavioral intention is determined by attitude and perceived usefulness. (Davis, 1989) suggest that user motivation can be explained by three factors: perceived usefulness, perceived ease of use, and attitude towards using the system. According to Venkatesh behavioral intention is the degree to which a person has formulated conscious plans to perform or not to perform some specified 
future behavior. (Venkatesh et al., 2003) indicate that "UTAUT model explains approximately $70 \%$ of variance in behavioral intention". (C. Evans et al., 2014) states that IU social media is the voluntary and cognitive representation of the user's readiness to actually use the social media.

Hypothesis H7-1: Attitude toward advertisement has a positive effect on intention to use Social Media Marketing.

Hypothesis H7-2: Attitude toward EWOM has a positive effect on intention to use Social Media Marketing.

\section{Research methodology}

The research method chosen for this study is done through quantitative methods to test the research model and hypotheses. Data were collected using direct customer interview technique by formal questionnaire with sample size $n=416$. The main subjects of this study are Internet and social media users, and over the age of 18. Data were collected through both online and paper questionnaires between December 2019 and May 2020. Participants in the paper survey were mainly students at Universities. learn, this is the object has a lot of interaction with social networks. Meanwhile, for the online survey, the questionnaire was built on the Google Forms system, a system that creates and analyzes the survey forms for free, which is then sent to the survey participants by transmission. In social media, participants who responded to the online questionnaire were also asked to forward the questionnaire to their friends.

In this study the survey items were adapted from previous literature related to UTAUT, TAM, and social media. Items were included with minor modification to fit in the perspective of social media marketing. Constructs of UTAUT including effort expectancy (ease of use), social influence and facilitating conditions were measured by 9 items which borrowed from Taprial \& Kanwar,(2012); Davis, (1989); Venkatesh et al., (2003); Liwei Chen, (2014). Constructs of TAM including perceived usefulness, attitude towards advertisement, attitude towards EWOM, intention to use SMM were measure by 14 items borrowed from previous studies (Davis, 1989; Vinerean et al., 2013; Lin, 2008; Liwei Chen, 2014). 
Table 1. Summary of scales

\begin{tabular}{|c|c|c|c|}
\hline Variables & Code & Number of items & Scale \\
\hline Effort expectancy & EE & 4 & \multirow{9}{*}{ Likert 5 point } \\
\hline Social influence & SI & 2 & \\
\hline Facilitating condition & FC & 3 & \\
\hline Perceived usefulness & PU & 4 & \\
\hline Involvement & IN & 10 & \\
\hline Perceived risk & PR & 3 & \\
\hline Attitude towards EWOM & $\mathrm{AW}$ & 4 & \\
\hline Attitude towards advertisement & AA & 6 & \\
\hline Intention to use SMM & IU & 5 & \\
\hline \multicolumn{2}{|l|}{ Total } & 41 & \\
\hline
\end{tabular}

Source: own study

\section{Data analysis}

\subsection{Testing of scales}

\subsubsection{Evaluating scales by using Cronbach Alpha reliability coefficient}

The reliability coefficient of the model will be presented in Table 2 below. The results of the reliability test of the scale with Cronbach Alpha coefficient, the components of the scale with Crobach Alpha coefficient are mostly accepted in terms of reliability (greater than the required level of 0.7). The Cronbach alpha analysis process has eliminated a Social influence factor due to its lower reliability of 0.7. Besides that, the following two observed variables have also been removed to improve reliability: ee2, in6. 
Table 2. Cronbach Alpha results

\begin{tabular}{l|c|c|c}
\multirow{2}{*}{\multicolumn{1}{c}{ Variable }} & Number of observed variables & \multirow{2}{*}{$\begin{array}{c}\text { Cronbach's } \\
\text { Alpha }\end{array}$} \\
\cline { 2 - 4 } & Before & After & .754 \\
\hline Perceived usefulness (PU) & 4 & 3 (remove EE2) & .705 \\
\hline Effort expectancy (EE) & 4 & 9 (remove IN6) & .805 \\
\hline Involvement (IN) & 10 & 2 & .628 \\
\hline Social influence (SI) & 2 & 3 & .701 \\
\hline Perceived risk (PR) & 3 & 3 & .759 \\
\hline Facilitating condition (FC) & 3 & 6 & .719 \\
\hline Attitude towards advertisement (AA) & 6 & 4 & .819 \\
\hline Attitute towards EWOM (AW) & 5 & 5 & .835 \\
\hline Intention to use (IU) & Source: own study & & \\
\hline
\end{tabular}

\subsubsection{Exploratory Factor Analysis (EFA)}

The EFA method was used for the remaining 39 observed variables, including 24 observed variables of the independent factors and 15 observed variables of the dependent factors, using the Principal Axis Factoring method with rotation Promax and stop when extracting elements with Eigenvalues is 1 . The scales will be assessed by the discovery factor analysis method based on the following criteria: factor loading is above 0.5 ; Total variance extracted $\geq 50 \%$; $\mathrm{KMO} \geq 0.5$, Barlett test has statistical significance (Sig <0.05).

\section{EFA for independent variables}

Table 3 presents the EFA results for the independent variables of the model. . The results extracted 6 factors as follows:

Factor 1: Consists of FC1, FC2, FC3, IN1, EE3, and EE4 are named as "Facilitating condition"

Factor 2: Including IN5, IN7, IN8, IN9, IN10 is named as "Involvement" 
Factor 3: Including EE1, PU4 is named "Effort expectancy"

Factor 4: Including PR1, PR2, PR3 named as "perceived risk"

Factor 5: Including PU1, PU2, PU3 is named "perceived usefulness"

Factor 6: Including IN3, IN4 in terms of content value will be named "Search level - SL" This is a newly created factor.

The total variance extracted (Total variability explained) is equal to 53,132\% (> $50 \%) . \mathrm{KMO}=0.870(>0.5)$ and Bartlett's Test is statistically significant (Sig $=0.000$ $<0.05)$. The data obtained satisfies the above conditions, proving that the factor analysis of EFA is consistent with the data.

\section{EFA for the dependent variables}

Table 4 presents the EFA analysis results for the dependent variables. After analysing 3 factor of dependent variables, there are still 3 factors:

Factor 1: Including AW1, AW2,AW3, AW4 is named "Attitude towards EWOM". Factor 2: Including IU1, IU2, IU3, IU4, IU5 is named as "Intention to use"

Factor 3: Including AA2, AA3, AA4, and AA6 is named as "Attitude towards advertisement"

The EFA for the dependent variables is also consistent with the data because the total variance extracted is $51,160 \%(>50 \%) . \mathrm{KMO}=0.900(>0.5)$ and the Bartlett test is statistically significant $(\mathrm{Sig}=0.000<0.05)$. Table 4 EFA analysis results for the dependent variables

Table 3. EFA for Independent variables

\begin{tabular}{|c|c|c|c|c|c|c|}
\hline \multicolumn{7}{|c|}{ Pattern Matrix } \\
\hline & \multicolumn{6}{|c|}{ Factor } \\
\hline & 1 & 2 & 3 & 4 & 5 & 6 \\
\hline $\mathrm{fc}_{\mathrm{c}} 2$ & .774 & & & & & \\
\hline fc3 & .759 & & & & & \\
\hline fc1 & .676 & & & & & \\
\hline ee3 & .597 & & & & & \\
\hline ee4 & .568 & & & & & \\
\hline in1 & .554 & & & & & \\
\hline in9 & & .804 & & & & \\
\hline
\end{tabular}




\begin{tabular}{|c|c|c|c|c|c|c|}
\hline in8 & & .796 & & & & \\
\hline in7 & & .712 & & & & \\
\hline in10 & & .650 & & & & \\
\hline in5 & & .530 & & & & \\
\hline pu4 & & & .800 & & & \\
\hline ee1 & & & .799 & & & \\
\hline pr2 & & & & .731 & & \\
\hline pr1 & & & & .660 & & \\
\hline pr3 & & & & .593 & & \\
\hline pu1 & & & & & .717 & \\
\hline pu2 & & & & & .685 & \\
\hline pu3 & & & & & .564 & \\
\hline in4 & & & & & & .939 \\
\hline in3 & & & & & & .676 \\
\hline Eigenvalues & 5.919 & 3.008 & 1.666 & 1.286 & 1.005 & .916 \\
\hline Variance extracted & 25.977 & 38.232 & 43.858 & 47.802 & 50.935 & 53.132 \\
\hline
\end{tabular}

Source: own study

Table 4. EFA for dependent variables

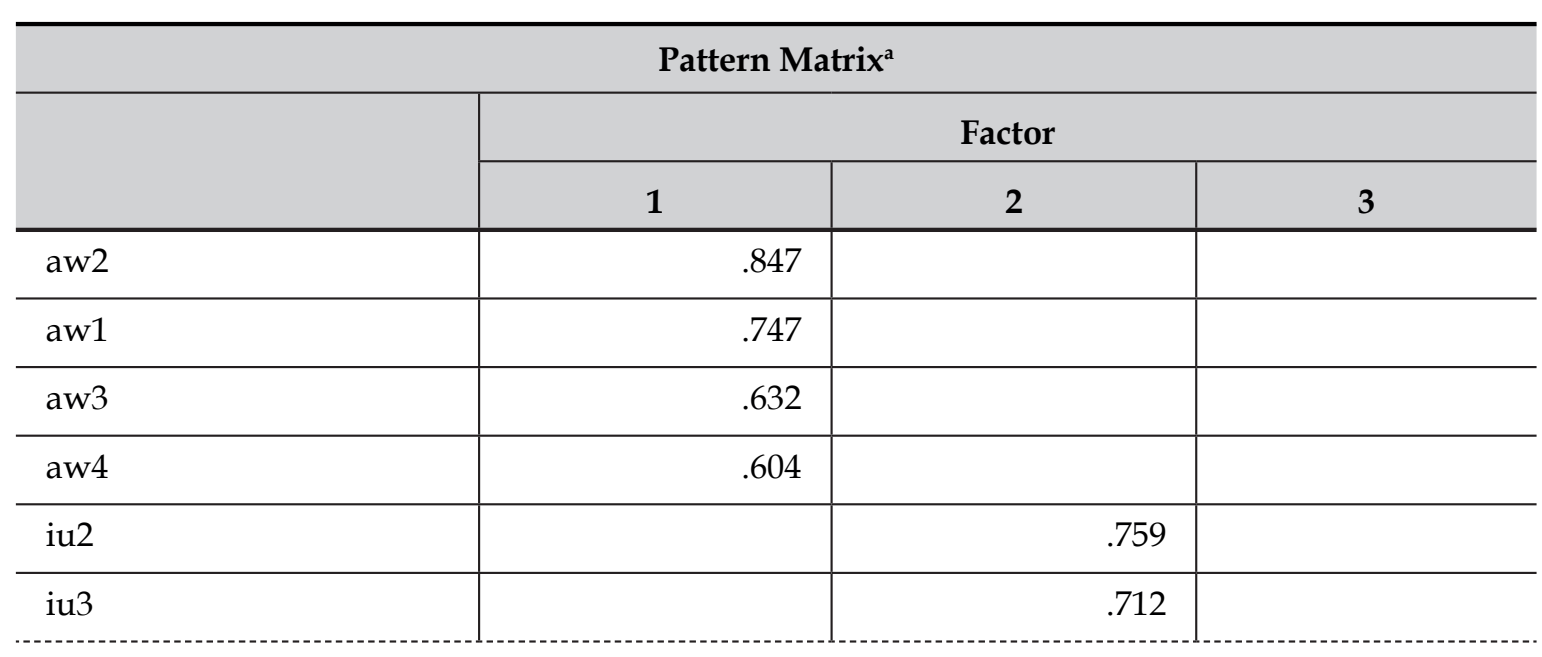




\begin{tabular}{|c|c|c|c|}
\hline iu5 & & 639 & \\
\hline iu1 & & .587 & \\
\hline iu4 & & .537 & \\
\hline aa4 & & & .746 \\
\hline aa2 & & & .642 \\
\hline aa3 & & & .566 \\
\hline aa6 & & & .510 \\
\hline Eigenvalues & 5.457 & 1.521 & 1.092 \\
\hline Variance extracted & 38.364 & 46.400 & 51.160 \\
\hline
\end{tabular}

Source: own study

Thus, the EFA analysis results show that it is necessary to readjust the observed variables in accordance with the data and the relationship between them. Therefore, in the original proposed research model, the "social influence" factor will be removed and will be replaced by a new factor called "level of search", corresponding to this, the hypotheses new:

Hypothesis H2-1: Search level has a positive effect on the attitude toward advertisement on social media.

Hypothesis H2-2: Search level has a positive effect on the attitude toward EWOM on social media.

\subsubsection{Verify the scale with CFA}

To measure the relevance of the market data model, this study uses four main indicators, namely Chi-squared, appropriate index comparing CFI (Comparative Fit Index), GFI index (Goodness of Fit Index) and the RMSEA (Root Mean Square Error Approximation). If a model receives a GFI and CFI values of 0.9 to 1 , RMSEA is $<0.08$, then the model is considered suitable for market data. CFA results show that the model has 556 degrees of freedom. CFA results show that the model is considered appropriate: $(\chi 2(556)=1069,476$, Chi-square $/ \mathrm{df}=1,924(<3)$, TLI $=$ 0.9908 (> 0.9), CFI = 0.918 (> 0.9), GFI = 0.887, RMSEA = $0.047(<0.08)$.

To build validity, two convergent and discriminant checks are performed:

1. The convergence validity is assessed by checking the total reliability and extracted variance (AVE): The total reliability of variables varies from 0.773 to 
$0.852(>0.7)$, the extracted variance AVE The range from 0.506 to $0.671(>0.5)$ indicates the convergence scale is reached.

2. The discriminant validity, table 5 shows the square root of AVE (located in bold diagonal lines) for each concept is greater than the correlation coefficient between one element and the others, showing that the scale has discriminant value. This measurement model is consistent with market data and there is no case where the errors of the variables are correlated with each other, so the observed variable is unidimentional.

Table 5. CR, AVE, Correlations and Root square of AVE

\begin{tabular}{l|l|l|l|l|l|l|l|l|l|l|l}
\hline & CR & AVE & IU & EE & IN & FC & AA & AW & PR & PU & SL \\
\hline IU & 0.837 & 0.508 & $\mathbf{0 . 7 2 3}$ & & & & & & & & \\
\hline EE & 0.777 & 0.636 & 0.450 & $\mathbf{0 . 7 9 8}$ & & & & & & & \\
\hline IN & 0.852 & 0.506 & 0.544 & -0.006 & $\mathbf{0 . 6 9 5}$ & & & & & & \\
\hline FC & 0.818 & 0.529 & 0.581 & 0.557 & 0.237 & $\mathbf{0 . 7 5 5}$ & & & & & \\
\hline AA & 0.763 & 0.509 & 0.722 & 0.274 & 0.690 & 0.527 & $\mathbf{0 . 7 7 0}$ & & & & \\
\hline AW & 0.822 & 0.537 & 0.635 & 0.500 & 0.203 & 0.716 & 0.551 & $\mathbf{0 . 7 3 3}$ & & & \\
\hline PR & 0.703 & 0.541 & 0.325 & 0.144 & 0.424 & 0.339 & 0.495 & 0.252 & $\mathbf{0 . 6 6 4}$ & & \\
\hline PU & 0.757 & 0.511 & 0.631 & 0.640 & 0.290 & 0.706 & 0.604 & 0.652 & 0.186 & $\mathbf{0 . 7 1 5}$ & \\
\hline SL & 0.803 & 0.671 & 0.593 & 0.445 & 0.364 & 0.512 & 0.455 & 0.466 & 0.259 & 0.621 & $\mathbf{0 . 8 1 9}$ \\
\hline
\end{tabular}

Source: own study

\subsection{Testing research model and hypotheses}

Based on the linear structure model with ML (Maximum Likelihood) estimation, the author conducts tests of the hypotheses as well as the suitability of the construction model with market data as shown in figure 2. 


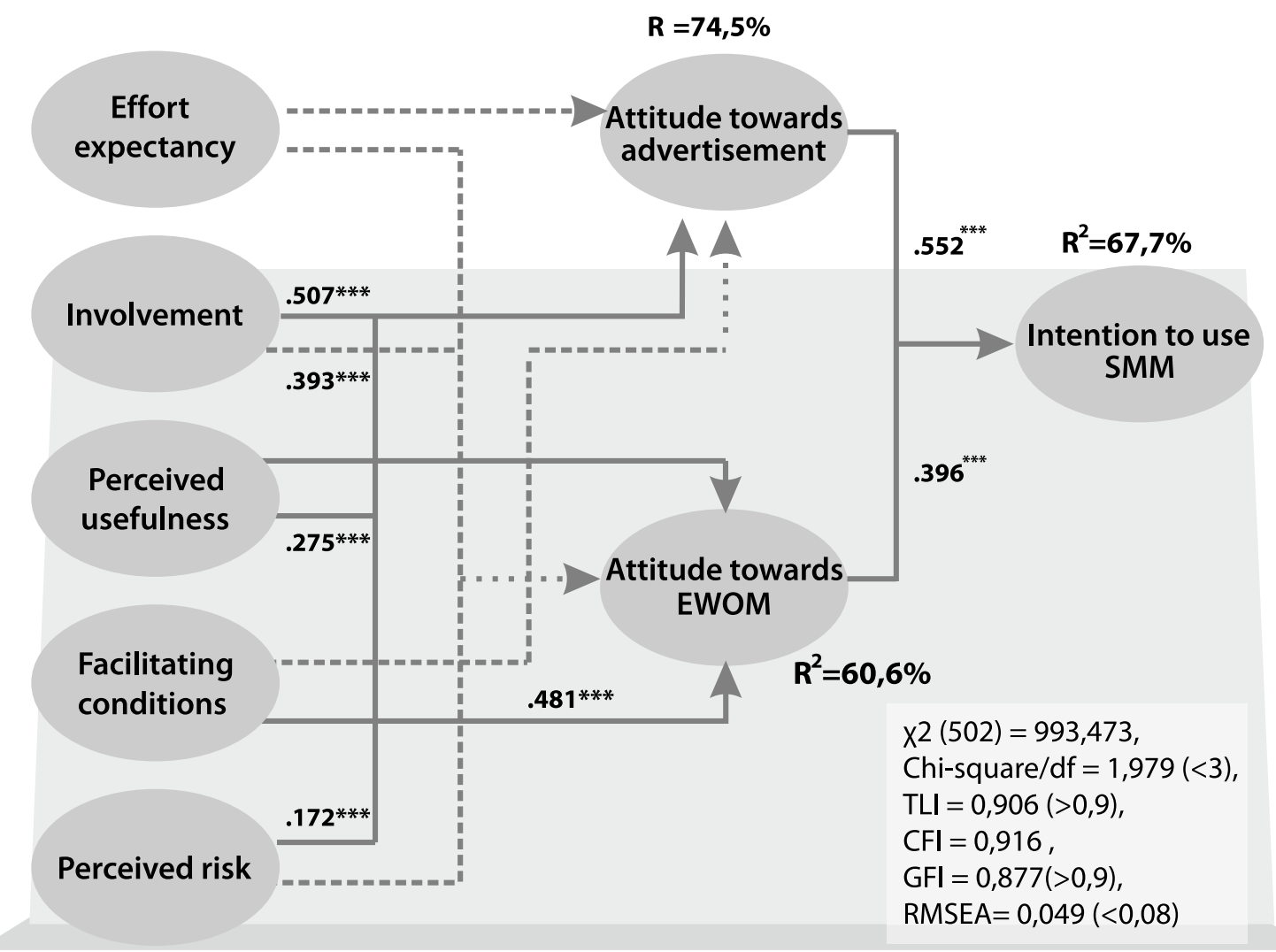

Figure 2. Standardized Structural Equational Model (SEM)

Source: own study

The results show that the theoretical model has 502 degrees of freedom. SEM results show that the model is compatible with market data: $\chi 2(502)=993,473$, Chi-square $/ \mathrm{df}=1,979(<3), \mathrm{TLI}=0.9906(>0.9), \mathrm{CFI}=0.916, \mathrm{GFI}=0.887(>0.9)$, RMSEA $=0.049(<0.08)$ (satisfactory). Table 5 presents the results and statistical significance of the estimates corresponding to the research hypotheses.

Table 6. Non-standardized estimated regression results

\begin{tabular}{c|c|c|c|c|c|c}
\hline $\begin{array}{c}\text { Hypoth- } \\
\text { esis }\end{array}$ & Relationship & $\begin{array}{c}\text { Esti- } \\
\text { mated } \\
\text { regres- } \\
\text { sion }\end{array}$ & S.E & C.R & $\begin{array}{c}\text { P- } \\
\text { value }\end{array}$ & $\begin{array}{c}\text { Accepted/ } \\
\text { rejected }\end{array}$ \\
\hline H 1-1 & $\rightarrow$ Attitude towards advertisement & -.027 & .067 & -.410 & .681 & Rejected \\
\hline
\end{tabular}

87

NGUYENTHI PHUONG THAO

NGUYENVAN ANH 


\begin{tabular}{|c|c|c|c|c|c|c|}
\hline H 1-2 & $\begin{array}{c}\text { Effort expectancy } \\
\rightarrow \text { Attitude towards EWOM }\end{array}$ & .088 & .071 & 1.239 & .215 & Rejected \\
\hline H 2-1 & $\begin{array}{c}\text { Search level } \rightarrow \text { Attitude towards } \\
\text { advertisement }\end{array}$ & -.022 & .053 & -.417 & .676 & Rejected \\
\hline H 2-2 & $\begin{array}{c}\text { Search level } \rightarrow \text { Attitude towards } \\
\text { EWOM }\end{array}$ & .060 & .055 & 1.102 & .270 & Rejected \\
\hline Н 3-1 & $\begin{array}{c}\text { Facilitating conditions } \\
\rightarrow \text { Attitude towards advertisement }\end{array}$ & .110 & .084 & 1.306 & .192 & Rejected \\
\hline Н 3-2 & $\begin{aligned} & \text { Facilitating conditions } \\
\rightarrow & \text { Attitude towards EWOM }\end{aligned}$ & .492 & .097 & 5.048 & .000 & Accepted \\
\hline H 4-1 & $\begin{array}{c}\text { Perceived usefulness } \\
\rightarrow \text { Attitude towards advertisement }\end{array}$ & .472 & .119 & 3.971 & .000 & Accepted \\
\hline H 4-2 & $\begin{array}{c}\text { Perceived usefulness } \\
\rightarrow \text { Attitude towards EWOM }\end{array}$ & .321 & .121 & 2.655 & .008 & Accepted \\
\hline H 5-1 & $\begin{array}{c}\text { Involvement } \rightarrow \text { Attitude towards } \\
\text { advertisement }\end{array}$ & .501 & .064 & 7.857 & .000 & Accepted \\
\hline H 5-2 & $\begin{array}{c}\text { Involvement } \rightarrow \text { Attitude towards } \\
\text { EWOM }\end{array}$ & .039 & .058 & .675 & .500 & Rejected \\
\hline H 6-1 & $\begin{array}{c}\text { Perceived risk } \\
\rightarrow \text { Attitude towards advertisement }\end{array}$ & .208 & .073 & 2.859 & .004 & Accepted \\
\hline H 6-2 & $\begin{array}{c}\text { Perceived risk } \\
\rightarrow \text { Attitude towards EWOM }\end{array}$ & .001 & .075 & .018 & .985 & Rejected \\
\hline H 7-1 & $\begin{array}{c}\text { Attitude towards advertisement } \rightarrow \\
\text { Intention to use SMM }\end{array}$ & .580 & .066 & 8.838 & .000 & Accepted \\
\hline H 7-2 & $\begin{array}{c}\text { Attitude towards EWOM } \rightarrow \text { Inten- } \\
\text { tion to use SMM }\end{array}$ & .429 & .065 & 6.615 & .000 & Accepted \\
\hline
\end{tabular}

The non-normalized estimation results of the main parameters in the theoretical model presented in the table above indicate whether the relationship between the independent and dependent variables is statistically significant and the normalized coefficients. The figure shown in the figure above shows the impact of the independent and dependent variables. The results showed that there was no statistical evidence of the impact of the Effort expectancyfactor, 
the level of search on the attitude towards advertising as well as the attitude on e-wom, which means the hypotheses $\mathrm{H} 1$ and $\mathrm{H} 2$ were rejected. There is also no statistical evidence of the impact of facilitating conditions on attitudes towards advertisement (H3-1); the impact of Involvement on e-wom (H5-2), and the impact of perceived risk on e-wom (H6-2) means hypotheses H3-1, H5-2 and H6-2 were rejected.

Meanwhile, hypotheses H3-2, H4, H5-1, H6 and H7 all have statistical evidence to accept the hypothesis. That is, there exists a relationship between the elements according to the statement of the stated hypothesis. Specifically, the more favorable the condition of using social media, the more positive the attitude towards e-wom (H3-2), with standardized beta of 0.481 at 99\% significance level; The higher the perceived usefulness of social media marketing, the more positive the user attitude towards social media advertising (H4-1), with a standardized beta of 0.393 at the confident level 99\%; The higher the perceived usefulness of social media marketing, the more positive the user attitude towards e-wom (H42), with a standardized beta of 0.275 at $99 \%$ significance level; The higher the level of involvement $\mathrm{n}$ in social media, the more positive its influence on user attitudes to social media advertising (H5-1), with a standardized beta of 0.507 in $99 \%$ significance level; The more positive a user is about social media advertising, the more likely they are to use social media marketing (H7-1), with a standardized beta of 0.552 at a meaningful level $99 \%$; and the more positive a user's attitude about e-wom is, the stronger their intention to receive marketing through social media (H7-2), with a standardized beta of 0.396 at 99\% significance level ;

In addition, Involvement, perceived usefulness, and perceived risk factors explain $74.5 \%$ of users' attitudes towards advertisement. Among the 3 factors above, the involvement has the most strongly affects (standardized $\beta=0.50$ ). Perceived usefulness factors and facilitating conditions explain $60.6 \%$ of users' attitudes towards electronic word of mouth, among them the most powerful is facilitating condition factors (standardized $\beta=0.481$ ).

\section{Conclusions}

From the results of the analysis above, it can be said that if users have a positive attitude towards online advertising and social media comments and reviews, they will intend to receive marketing through transmission, higher social communication. The above results also indicate that the level of participation, useful awareness and risk awareness also have a direct influence on attitudes to advertising on social media. This means that users have high expectations 
of the ease of using social media sites with a variety of means to access social media and the social impact of buying through social media. Social media will have a positive attitude towards advertising reception, which has been tested and proven through data analysis.

Moreover, facilitation conditions and perceived usefulness can be considered as the most important premises of attitudes to electronic word of mouth. These premises also have indirect effects on the intention to receive Marketing through social media. This means that users are influenced by their surroundings and surroundings, with a greater involvement in social media sites and a positive awareness of the usefulness of social media marketing.

The involvement will have a positive attitude through reviews and comments on products and services on social media. Therefore, to promote a group of consumers to receive marketing through social media, it is necessary to develop social media sites in an easy-to-use way to increase their awareness of usefulness as well as minimize aware of their risks in social media marketing.

An interesting fact from the research results is that most of the survey respondents prefer advertising methods through Youtube and Facebook. From these findings, marketers can see that selecting the right social media to advertise their products and services is a key to attracting customers. products through social media platforms.

\section{Limitations and advice}

The main objective of this study is to consider the relevance of marketing elements through social media and consumers' intention to receive SMM. Although the research has partially achieved its objectives, due to limitations in knowledge and understanding, there are certain limitations and flaws. Based on research results and limitations, some recommendations for future studies are as follows:

First, the first restriction is on a sample selected in a convenient manner due to time and research costs. Therefore, the comprehensiveness of the findings is a limitation. Therefore, the following studies may increase the sample size or use the probability sampling method. Secondly, the limitation of the research is that the scale is inherited and translated into English words, so during the translation process, it may not convey all the content of the question and may cause confusion for people surveyed from there resulted in some responses being inaccurate or untrue. This leads to the results of EFA analysis which have not achieved the desired results. Just as limitations in measuring tools do not 
have enough information to assess consumer behavior, so it is advisable that future studies should focus on completing the measurement criteria, language assistance services from language experts may be used.

Thirdly, as this is one of the first studies in Vietnam in social media marketing, there are very few studies that can be used for further reference. Besides, the factors in the study are distilled from theoretical studies, so they may be affected by other peripheral factors. In addition, there are still other relationships that need to be examined between variables. The research of integrated model survey was developed from UTAUT and TAM theory but the research model still needs to be revised to be more complete and accurate.

\section{Summary}

Behavioral Intention Of Young Consumers Towards The Acceptance Of Social Media Marketing in Emerging Markets The study identifies the factors that influence marketing through social media of users in the Vietnam market, conducted through qualitative and quantitative methods. The research results show that Intention to use social media marketing is directly affected by Attitude towards advertisement and Attitude to electronic words of mouth. Additionally, perceived usefulness, Search Level and Perceived risk are factors that directly affect Attitude towards advertisement. Whereas, material condition and perceived usefulness are factors that affect Attitudes towards electronic words of mouth. This study also provides some implications for marketers through social networks to increase the confidence and effectiveness of marketing campaigns and programs through this channel.

Keywords: Social media marketing, EWOM, attitude towards advertisement, intention to use.

JEL

Classification: M10, M3, M31

\section{References}

Agrawal, S., Kaur N. (2015). Influence of Social Media Marketing in Indian Pharmaceutical Industry, Int. J. Adv. Res. Innov., Vol. 3, No. 4, pp. 735-738. Al Qeisi, K. I., Al-Abdallah, G. M. (2014). Website Design and Usage 
Behaviour: An Application of the UTAUT Model for Internet Banking in UK, Int. J. Mark. Stud., Vol. 6, No. 1, pp. 75-89.

Balaid, A., Yaslam Almatari, A., Iahad, N. (2013). Factors influencing students' intention to use mlearning, Vol. 5.

Bansal, E. (2015). Social Media Marketing: - Prerequisites For The Effective Content Success, Int. J. Sci. Res. Educ., Vol. 3, No. 7, pp. 3914-3921.

Carlsson, C., Carlsson, J., Hyvönen, K., Puhakainen, J., Walden, P. (2006). Adoption of mobile devices/services - Searching for answers with the UTAUT, Proc. Annu. Hawaii Int. Conf. Syst. Sci., Vol. 6, No. C, pp. 1-10.

Davis, F. D. (1989). Perceived Usefulness, Perceived Ease of Use, and User Acceptance of Information Technology, MIS Q., Vol. 13, No. 3, pp. 319-340. Gardner, C., Amoroso, D. L. (2004). Development of an instrument to measure the acceptance of Internet technology by consumers, 37th Annu. Hawaii Int. Conf. Syst. Sci. 2004. Proc., January 2004, p. 10.

Gentry, L., Calantone, R. (2002) A comparison of three models to explain shop-bot use on the web, Psychol. Mark., Vol. 19, No. 11, pp. 945-956.

Guy, I., Zwerdling, N., Ronen, I., Carmel, D., Uziel E. (2010). Social media recommendation based on people and tags, Proceeding 33rd Int. ACM SIGIR Conf. Res. Dev. Inf. Retr. - SIGIR '10, no. Lc, p. 194.

Knutsen, L. A. (2005) M-service expectancies and attitudes: Linkages and effects of first impressions, Proc. Annu. Hawaii Int. Conf. Syst. Sci., Vol. 00, No. 2054, p. 84.

Lee, Y., Kozar, K. A., Larsen, K. R. T., Lee, Y., Kozar, K. A., Larsen, K. R. T. (2003). The Technology Acceptance Model: Past, Present, and Future, Commun. Assoc. Inf. Syst., Vol. 12, No. 50, pp. 752-780.

Lim, N. (2003). Consumers' perceived risk: Sources versus consequences, Electron. Commer. Res. Appl., Vol. 2, No. 3, pp. 216-228.

Longart, P. (2010). What drives word-of-mouth in restaurants?, vol. 22.

Luo, X., Zhang, J., Duan, W. (2013). Social media and firm equity value, Inf. Syst. Res., Vol. 24, No. 1, pp. 146- 163.

Mangold, W. G., Faulds, D. J. (2009). Social media: The new hybrid element of the promotion mix, Bus. Horiz., Vol. 52, No. 4, pp. 357-365.

Martins, C., Oliveira, T., Popovič, A. (2014). Understanding the internet banking adoption: A unified theory of acceptance and use of technology and perceived risk application, Int. J. Inf. Manage., vol. 34, no. 1, pp. 1-13, 2014.

Neti, M. S. (2011). SOCIAL MEDIA AND ITS ROLE IN MARKETING, Int. J. Enterp. Comput. Bus. Syst., Vol. 1, No. 2, p. 16.

O'Cas,s A., Fenech, T.(2003). Web Retailing Adoption: Exploring the Nature of Internet Users Web Retailing Behaviour, Vol. 10.

Pan, J., Vorvoreanu, M., Zhou, Z. (2014). Social media adoption in disaster restoration industry, Constr. Innov., Vol. 14, No. 3, pp. 346-369. 
Parra-López, E., Bulchand-Gidumal, J., Gutiérrez-Taño, D., Díaz-Armas, R. (2011). Intentions to use social media in organizing and taking vacation trips, Comput. Human Behav., Vol. 27, No. 2, pp. 640-654.

Petty, R. E., Cacioppo, J. T., Goldman, R. (1981). Personal involvement as a determinant of argument-based persuasion., J. Pers. Soc. Psychol., Vol. 41, No. 5, pp. 847-855.

Romero, D. M., Galuba, W., Asur, S., Huberman, B. A. (2011). Influence and Passivity in Social Media.

Rouse, M., What is social media?, techtarget.com. [Online]. Available: https://whatis.techtarget.com/definition /social-media. (Accessed: 15Apr-2018).

Sundaravej, T. (2010). Empirical Validation of Unified Theory of Acceptance and Use of Technology Model, Vol. 13.

Thackeray, R., Neiger, B. L., Hanson, C. L., Mckenzie, J. F. (2008). Enhancing Promotional Strategies Within Social Marketing Programs: Use of Web 2.0 Social Media, Health Promot. Pract., Vol. 9, No. 4, pp. 338- 343.

Venkatesh, V., Morris, M. G., Davis, G. B., Davis, F. D. (2003). User Acceptance of Information Technology: Toward a Unified View, Source MIS Q., Vol. 27, No. 3, pp. 425-478.

Venkatesh, V., Sykes, T. A., Zhang, X. (2011). Just what the doctor ordered': A revised UTAUT for EMR system adoption and use by doctors," Proc. Annu. Hawaii Int. Conf. Syst. Sci., pp. 1-10.

Vinerean, S., Cetina, I., Dumitrescu, L., Tichindelean, M. (2013) The Effects of Social Media Marketing on Online Consumer Behavior, Int. J. Bus. Manag., Vol. 8, No. 14, pp. 66-79. 